8-1-2011

\title{
Exploring The Developmental Potential Of Leader-Follower Interactions: A Constructive-Developmental Approach
}

\author{
Sorin Valcea \\ Cleveland State University, s.valcea@csuohio.edu \\ Maria R. Hamdani \\ University of Akron, hamdani@akron.edu \\ M. R. Buckley \\ University of Oklahoma
}

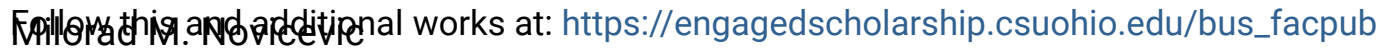

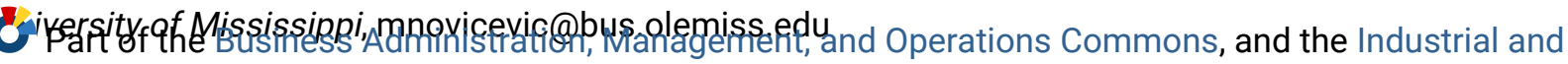

Organizational Psychology Commons

How does access to this work benefit you? Let us know!

\section{Publisher's Statement}

NOTICE: this is the author's version of a work that was accepted for publication in The leadership Quarterly. Changes resulting from the publishing process, such as peer review, editing, corrections, structural formatting, and other quality control mechanisms may not be reflected in this document. Changes may have been made to this work since it was submitted for publication. A definitive version was subsequently published in The Leadership Quarterly, 22, 4, 08-01-2011 10.1016/j.leaqua.2011.05.003

\section{Original Published Citation}

Valcea, S., Hamdani, M.R., Buckley, M.R., \& Novicevic, M.M. (2011). Exploring the developmental potential of leader-follower interactions: A constructive-developmental approach. The Leadership Quarterly, 22(4), 604-615. doi: 10.1016/j.leaqua.2011.05.003

This Article is brought to you for free and open access by the Monte Ahuja College of Business at EngagedScholarship@CSU. It has been accepted for inclusion in Business Faculty Publications by an authorized administrator of EngagedScholarship@CSU. For more information, please contact library.es@csuohio.edu. 


\title{
Exploring the developmental potential of leader-follower interactions: A constructive-developmental approach
}

\author{
Sorin Valcea ${ }^{a}$, Maria Riaz Hamdani ${ }^{\text {b}}$, M. Ronald Buckley ${ }^{\text {c, } *}$, Milorad M. Novicevic ${ }^{\text {d }}$ \\ a Department of Management, School of Business, Washburn University Topeka, KS, 66621, USA \\ ${ }^{\mathrm{b}}$ Department of Management, College of Business Administration, University of Akron, Akron, OH,44325-4733, USA \\ ${ }^{c}$ Division of Management and Entrepreneurship, Price College of Business, University of Oklahoma, Norman, OK, 73019, USA \\ ${ }^{\mathrm{d}}$ Department of Management, School of Business Administration, University of Mississippi, University, MS 38677, USA
}

Oscar Wilde, the great Irish writer and poet, once said: "The secret of life is in art." Art sometimes provides us with searing insight into the human condition. Consider the case of Eugene, a secondary school teacher who is profoundly transformed by the wisdom of his seventh grade student, Trevor. This twelve-year-old boy is a highly inspirational and transformational character in a 2000 movie Pay it Forward based on a novel by Catherine Hyde (2000). Trevor manages to bring about significant positive changes in a wide circle of people around him, including his instructor "Eugene" and mother "Arlene." Through his daily interactions and dialogs, he convinces people around him to live according to the notion of generalized reciprocity or pay-it-forward. Trevor's transformational role in his relationships challenges the generally accepted directionality of developmental influence in conventional teacher-student, parentchild, or leader-follower relationships. This work of art has revealed an important and not very well kept secret in life: Just as leaders most certainly develop followers, followers have an important developmental influence upon leaders.

Proponents of transformational leadership have proffered that it is the transformational leader who facilitates a positive change in the behaviors of others and in the performance of followers through their idealized persona, intellectual appeal, inspirational motivation, and individualized consideration (Avolio, Bass, \& Jung, 1999). However, some gainsay this notion and have suggested that the phenomenon of leadership and change cannot be completely understood when we ignore the reciprocal influence of followers. Recently, Drath (2001) elaborated on this idea by stressing that the real meaning of leadership as a collective phenomenon will not be comprehended in its entirety by focusing only on the "sparkling whitecaps we know as leaders." Rather, a more thorough reckoning requires us to understand that "in making leadership happen, we all swim together in the deep blue sea." (Drath, 2001, p. xviii).

In order to promote the suggestion that leadership is a collective phenomenon, it becomes important to understand how personal change and development occurs in a leader-follower dyad. A recent review of applications of constructive developmental theory in leadership research by McCauley, Drath, Palus, O'Connor, and Baker (2006) suggests that developmental potential in a

\footnotetext{
* Corresponding author at: Price College of Business, Division of Management, 307 W. Brooks, suite 308C, Norman, OK 73019 , USA. Tel.: + 1405 325 5729 (office).

E-mail address: mbuckley@ou.edu (M.R. Buckley).
} 
leader-follower dyad may have a significant relationship with what Loevinger and Blasi (1976) call ego development. An individual's stage of ego development represents a complex meaning-making system that governs and facilitates various psychological or developmental processes (Loevinger \& Blasi, 1976). In this paper, we use constructive developmental theory to suggest that, in a leader-follower dyad, the counterpart with a more complex and advanced ego level can influence the ego development of the less developed individual in the dyad. Moreover, we suggest that the quality of the leader-follower relationship will influence the degree to which leaders and followers can influence the ego development of each other.

We believe a constructive-developmental approach to the problem of developing successful leaders and followers is particularly useful, as research has shown that people who operate from advanced sense-making structures are more strategic (Bartunek, Gordon, \& Weathersby, 1983; Hirsch, 1988; Merron, Fisher, \& Torbert, 1987; Smith, 1980), allocate resources more effectively and efficiently (Torbert, 1987a), generate more revenues (Hirsch, 1988; Torbert, 1991), and are perceived to be more effective in leadership roles by their peers and subordinates (Strang \& Kuhnert, 2009). Thus, the advancement sense-making principles of individuals working at various levels in organizations can increase the organizational capacity to better frame complex business problems and craft solutions that fulfill individuals' needs and organizational demands (Bartunek et al., 1983; Weick, 1979). Moreover, by focusing on leader-follower interactions as a source of development for both leaders and followers, we make a number of important contributions to the leadership literature. First, compared to other developmental interventions proposed in the literature - such as action inquiry (Torbert,, \& Associates, 2004), changes in personal life or environment, external events (Rooke \& Torbert, 2005), developmental interventions (Palus \& Drath, 1995), and participation in communities of practice (Wenger \& Snyder, 2000) - leader-follower interactions have the advantage of being more continuous, complex, and prolonged in nature, aside from being ever-present in all organizations. Second, through our work we have broadened the application of constructive development theory in the leadership literature by highlighting ways in which followers can influence the ego development of their leaders; previous literature has largely ignored the developmental role of followers. Third, our model sheds some light on developmental mechanisms particular to each stage, instead of simply focusing on the characteristics of each stage. Fourth, by acknowledging the role of the quality of the leader-follower relationship (i.e., Leader-Member Exchange or LMX; Dansereau, Cashman, \& Graen, 1973), we specifically respond to McCauley et al.'s (2006) call for the integration of constructive developmental theory with other mainstream leadership theories. We start with a review of the main principles of constructive developmental theory. We then discuss how leader-follower interactions can promote ego development, and how LMX moderates this relationship. Lastly, we discuss the implications of our propositions for future research.

\section{Constructive developmental theory}

The work environment in today's knowledge-rich economy is characterized by rapid changes and increased levels of complexities (Cascio, 1995). The resulting new workplace demands are forcing businesses to attend more to enhancing the capabilities and potential of their employees (Mayo, 2000). As a response to the increased pressure to enhance the quality of human capital, organizations have started to view employee development as a much broader, ongoing process (Baldwin \& Magjuka, 1997). Leader-member interactions are a pervasive phenomenon in organizational life, making it an important mechanism of continuous human development and potential enrichment in the workplace. Moreover, the nature of the relationship between a leader and a follower influences outcomes at multiple levels by impacting employees' motivation, commitment, career outcomes, group performance, and organizational productivity and reputation (Henderson, Liden, Glibkowski, \& Chaudhry, 2009). Hence, significance of this relationship provides a compelling argument to explore its developmental potential. One framework that is particularly well-suited to explain the fundamental principles of evolution and growth in psychological capabilities is known as constructive developmental theory (Kegan, 1980). In this paper, we use constructive developmental theory to explicate the developmental potential of leader-follower dyadic interactions.

At the core of constructive developmental theory (CDT) are two primary aspects of development: (a) the sense-making system that regulates how people make sense of, and assign meaning to themselves and the surrounding world (i.e., developmental orders), and (b) how these meaning-making systems are constructed and reconstructed over time (i.e., developmental movement) (McCauley et al., 2006). The sense-making system consists of principles, beliefs, thinking patterns, and assumptions that govern the way individuals experience their lives. Researchers term this framework "constructive developmental" because it is concerned with the way people use sense-making systems to construct their life experiences and the way in which these meaning-making systems can develop over time (Helsing, Drago-Severson, \& Kegan, 2004).

According to constructive developmental theory, sense-making systems are not random or idiosyncratic in nature; instead these patterns evolve from simpler to more complex systems in a logical and a coherent manner. These sense-making patterns evolve by passing through distinct stages, a process that is called developmental movement (e.g., McCauley et al., 2006), or ego development (e.g., Loevinger \& Blasi, 1976). Each stage is stable for a durable period of time and is termed as a developmental order. The evolution from a lower and simpler order to a higher and more complex order is called developmental movement. Developmental movement can be conceptualized as a vertical growth where human consciousness is transformed to use more complex meaning making structures. The growth that occurs in developmental movement is different from the horizontal growth that an individual experiences within a particular order. The learning of new skills, expanding the domain of current knowledge, and going through various experiences that are similar in nature to past experiences are some examples of horizontal growth (Cook-Greuter, 2004).

Several constructive developmental frameworks have been proposed in the past, each suggesting different numbers of stages or development orders. McCauley et al. (2006) reviewed the most influential constructive developmental theories presented by 
Kegan (1982), Loevinger and Blasi (1976), Torbert (1987b), and Kohlberg (1969), and integrated these to propose three main sense-making stages: dependent order, independent order, and inter-independent order. A review of this literature suggests that there are four main facets of any developmental order: cognitive style, interpersonal orientation, conscious preoccupation, and mode of ethical judgment (Fisher \& Torbert, 1991; Loevinger \& Blasi, 1976; Loevinger \& Wessler, 1970). Each developmental stage is characterized by specific manifestations of these facets. The first facet, cognitive style, primarily represents the level of complexity in the manner one gains, stores, analyzes, and integrates information. People at the dependent order have a relatively simple view of the world. For example, a supervisor at the dependent order may attribute failure of his or her subordinate to a single cause such as lack of effort or laziness. In contrast, a supervisor operating at a more advanced developmental level (i.e., independent or inter-independent) is likely to have a broader view-point and may analyze a problem considering various factors, such as the context of assignment, circumstances of the failing individual, nature of the assigned task, and the complex interaction of a variety of factors in eliciting the failure.

The second facet, interpersonal orientation, explains how one views his or her relationships with others and how one understands these relationships. People at the dependent order are more demanding, and controlling in relationships. However, with advancement in sense-making systems, one begins to acknowledge the need for individual expression and freedom, and the inevitability of differences in relationships. Such orientation toward relationships results in more willingness to provide autonomy and freedom in relationships. A leader at the independent order may still interfere in followers' day-to-day affairs to protect them from making mistakes. However, a leader at an inter-independent developmental order would believe that others should be allowed to learn from their own mistakes.

The third facet, conscious preoccupation, describes the thoughts or motives which dominate one's mind and behavior. At a dependent order, one's dominant concern is social approval. However, as the sense-making system develops, one begins to focus on broader and more complex needs. At the independent order, system effectiveness and interaction between system and self becomes more important. Finally, at the inter-independent order, ongoing development of self and others becomes a primary focus and motive for behavior.

The fourth facet, mode of ethical judgment, refers to the way individuals make moral and ethical judgments and controls the impulsiveness in their nature. At the dependent order, social desirability is of prime value to the individual, and one defines an action as right and wrong according to social norms or group expectations. At the independent order, one starts appreciating individual differences and evaluating rules and norms according to his or her own principles. Thus, moral and ethical judgments are made on the basis of consequences of one's actions and not on the basis of others' approval. At the inter-independent order further complexities emerge in one's ethical reasoning. There is an increased awareness of inconsistency between one's espoused and enacted moral standards and values. The individual at this order deals with this conflict in a mature manner by understanding the underlying causes of such discrepancies and exploring ways to reconcile these differences. Moreover, at this stage the ethical reasoning is based on broader principles that one believes all humanity should follow.

These four facets are not, however, separate dimensions of the ego. Rather, the ego encompasses all four, such that a change in one facet will mean a change in all of the other facets (Loevinger \& Blasi, 1976). Each order, in essence, provides a broader and more complex paradigm for understanding oneself and the surrounding world. A change in paradigm, or a transition to a higher order, must involve, thus, a change in an individual's cognitive style, interpersonal style, conscious preoccupation and mode of ethical judgment. Given the interdependence of these ego stage facets, we focus on the two facets that are more salient in a work environment, with an understanding that any developmental interventions focused on these two facets are likely to affect the ego level as a whole. The two facets that are salient in work life are an individual's cognitive style and interpersonal orientation.

According to Loevinger and Blasi (1976), a change of paradigm is essentially an adaptive reaction to the continuous interaction between the individual and the environment. When people are confronted with new information, they may try to absorb this information within the current developmental order-a process called assimilation. However, when the new information does not fit the scheme, people adjust the current developmental order to the new information-a process called accommodation. Assimilation results in the stability of the current developmental order, while accommodation results in the evolution of the current order (i.e. developmental movement). What is intriguing about the findings of the constructive developmental literature is that most adults never progress beyond the dependent order, despite there being evidence that further development in adults is possible (Manners, Durkin, \& Nesdale, 2004; White, 1985), and that significant personal and professional benefits may result from functioning at an advanced stage (e.g., Hirsch, 1988; Manners \& Durkin, 2000; Smith, 1980; Torbert, 1991). The question then becomes what makes adult life and work life, in particular, less prone to development.

Research has suggested two primary reasons for a lack of advancement to higher developmental orders (e.g., Helsing et al., 2004; Loevinger \& Blasi, 1976; McCauley et al., 2006). The first reason for the stability of developmental orders is a lack of challenge in one's environment. Without challenge, conflicting information is quite scarce and there is little reason to engage in individual development. Therefore, individuals simply assimilate new information within the current framework of thinking. In fact, Block (1982) suggests that people have a tendency to find and inhabit comfortable niches in their work environment where they do not experience challenges that might encourage further development. The second condition that thwarts developmental movement is an environment which has ample challenges but lacks sufficient support for developmental movement to occur. Changing a frame of thinking entails a fear of losing meaning and creates an immunity to change (Kegan \& Lahey, 2001). Overcoming this immunity to change requires enough support in the environment to safely expose one's limiting assumptions and enable people to accommodate their current developmental orders to new information.

In order for developmental movement to occur, a delicate balance of support and challenge to the current framework of thinking must be attained (Kegan \& Lahey, 2001). New information may be resisted if it comes too soon or if it creates insecurity. Loevinger and 
Blasi (1976) suggested that good teachers and therapists create an environment of "unconditional positive regard", which works similarly to an "intrinsic parental valuation" to encourage the student or the patient to take on challenges. We argue that the same is true for leader-follower relations, and we structure our paper in two parts. First, we discuss the developmental interventions that leaders and followers can make to foster the development of the other party in the dyad. Second, we argue that these developmental interventions are more likely to result in ego development in the context of a high LMX (e.g., Dansereau et al., 1973) relationship.

\section{Challenging the current meaning making system}

Constructive-developmental researchers have proposed various mechanisms that facilitate developmental movement, such as action inquiry (Torbert, \& Associates, 2004), changes in personal life or environment, external events (Rooke \& Torbert, 2005), developmental interventions (Palus \& Drath, 1995), and participation in communities of practice (Wenger \& Snyder, 2000). Surprisingly, though, work relationships have not been proposed as developmental mechanisms in this literature, despite their ubiquitous nature in adult life. In the management literature, research on transformational leadership (e.g., Bass, 1985) and mentoring (e.g., Kram, 1983) has made substantial contributions to the understanding of developmental work relationships. However, both of these theories are somewhat unidirectional (i.e., the emphasis is on the development of the follower) and vague in terms of the underlying principles that make such efforts developmental in nature. For instance, transformational leadership theory suggests, through the concept of individualized consideration, that transformational (i.e., developmental) efforts must be tailored to the developmental needs of the target. Nevertheless, it leaves unanswered the question of what these needs may be and which mechanisms would be suitable for transformation of different individuals. Constructive development theory, in turn, has the advantage of providing an underlying framework that guides how individuals' needs, thought patterns, aspirations, and preoccupations are shaped by their developmental orders.

There are two primary mechanisms of psychological development: ontic, where development occurs as a result of natural maturation over one's lifetime, and agentic, where development is brought about by purposeful actions of a human agency (Laske, 1999). In this paper, we propose that leader-follower relationships can serve as an agentic mechanism of developmental movement. Previous research has indeed shown that more developed individuals can act as pacers for less developed individuals, such as teachers helping students (Kohlberg, 1987) and parents acting as pacers for children (Loevinger \& Blasi, 1976). In the leadership literature, Dvir and Shamir (2003) found that highly developed distant followers promoted more transformational behaviors in their leaders.

In a certain sense, leader-follower relationships are similar to teacher-student and parent-child relationships. In all these relationships one party has significantly more authority and power than the other. The party with more power and authority can then create opportunities for learning and development for the other, by providing appropriate teachings and activities for the other party. Unlike all parent-child relationships and most teacher-student relationships, however, leader-follower relationships are not constrained by age. In other words, there is a greater variety of age combinations, as either party can be the older of the two. Moreover, studies have shown that age is only correlated with ego development until early adulthood (Pfaffenberger, 2005). It follows that leader-follower relationships are characterized by a higher probability that the follower will be at a higher developmental stage than the leader, compared to other developmental relationships. In such cases, it is the follower who acts as a pacer for the leader, and not the other way around.

Because of the difference in authority between leaders and followers, the developmental mechanisms that each party can deploy, may be different. We focus on three primary means of exposing the limitations of a meaning-making system: delegation, participation, and feedback. Past research has shown that delegation (e.g., Klein, Ziegert, Knight, \& Yan, 2006; Leana, 1987), participation (e.g. Horgan \& Simeon, 1990), and feedback (DeRue \& Wellman, 2009) can foster the development of individuals. Manners and Durkin (2000) suggest that a successful developmental mechanism needs to meet certain criteria in order to foster transition to a higher order. More specifically, a developmental mechanism has to be disequilibrating in relation to the existing stage of development, personally salient, emotionally engaging (i.e., an experience that influences feelings and elicits emotional response such as anger, sympathy, pity, frustration, or happiness), and interpersonal in nature. In our treatment of feedback, participation and delegation, we emphasize how these behaviors can be exercised in ways that meet the requirements specified by Manners and Durkin (2000). Moreover, we discuss how these developmental mechanisms affect the two facets of ego (i.e., cognitive style and interpersonal style) that are of interest in this paper.

\subsection{Challenging dependent individuals}

\subsubsection{Development through delegation}

Delegation is a leader behavior which consists of assigning additional responsibilities and authority to subordinates (Yukl \& Fu, 1999). Delegation can promote individual achievement and build individual autonomy (Leana, 1987) and, hence, is particularly suited as a developmental mechanism for dependent individuals. Followers at this stage are not inclined toward taking personal initiatives or making independent decisions (Cook-Greuter, 2004). A dependent follower's cognitive style is marked by stereotype thinking and clichés, which translates into a preference for working according to clearly defined rules and regulations. In terms of interpersonal style, dependent followers define themselves through their relationships with others (Kegan, 1980). At this stage, social norms take precedence over individual needs (Torbert, 1987b). As a result, dependent followers see conflict as undesirable and disruptive. Overall, the primary work-related behaviors of dependent individuals are conformity to norms and rules, social desirability, and avoidance of conflict. Thoughtful delegation of assignment by a leader may promote development by offering an opportunity to try out new styles and behaviors in situations that matter (Feldman, 1988; McCauley, 1986). 
In order to progress to an independent order, a dependent-order follower needs to become aware of the limitations of his or her current sense-making systems. We define individualizing delegation as the delegation, by an independent or inter-independent leader, of assignments that render established rules and norms inadequate, and that place followers in situations of conflict of loyalty. In the absence of rules, norms, and established routines, dependent followers will be more aware of the need to develop their own standards of judgment (McCauley, Ruderman, Ohlott, \& Morrow, 1994). This will foster growth by creating disequilibrium in one's current cognitive style. Examples of individualizing delegation, where old norms and rules are rendered inadequate, may include assignments such as changes in job location (Nicholson, 1984), changes in job content or function (Nicholson \& West, 1988), and increase in scope of responsibility (McCall, Lombardo, \& Morrison, 1988). In all these situations, dependent followers experience disruption of routine and face unfamiliar job problems. We argue that an independent or an interindependent leader can use the disequilibrating potential of individualizing delegation to guide the dependent follower in accommodating his current cognitive style to the new information emerging in the environment.

We have defined individualizing delegation as the assignment of responsibility and authority in situations where established norms and rules are no longer adequate. For example, if a team member is assigned the role of group supervisor, she would be expected to use authority to ensure completion of tasks. This inevitability creates tension between one's identity as a peer and one's role as a supervisor. Thus, the concern for group cohesion - a central aspect of the interpersonal style of a dependent individual (Kuhnert, 1994) - will be apparent as a limitation when a dependent individual is split between conflicting loyalties because of individualizing delegation. Working in a diverse environment, for example, can be a disequilibrating experience for a dependent follower's interpersonal style. Kegan and Lahey (2001) gave an account of an African-American manager in a software company who was worried that moving up the corporate ladder would alienate him from the members of his own community and threaten his cultural identity. In response, he had developed a defense mechanism - sarcasm - to keep other executives at a distance and maintain his authentic bond with his racial group. Over the course of time, the manager was given various assignments that required collaboration with white executives. These assignments exposed the limiting assumptions of his interpersonal style. The delegated tasks encouraged him to re-examine his loyalty concerns and define his own standards and rules of functioning in a racially diverse executive team.

In sum, individualizing delegation is likely to be disequilibrating to the dependent individual's cognitive and interpersonal style. In addition, individualizing delegation is also likely to be personally salient, emotionally engaging, and interpersonal in nature. Delegated assignments involve an increased responsibility and are more salient to an individual than his regular work assignments because of a need to prove oneself again (McCauley et al., 1994). Moreover, delegated assignments are likely to be particularly salient to a dependent follower because these assignments symbolize the trust and respect expressed by the leader (Kuhnert, 1994), thus resonating with a dependent follower's concern for appreciation. The presence of loyalty conflict is likely to make this form of delegation more emotionally engaging and challenging at an interpersonal level, as the dependent follower is likely to be "torn" between conflicting loyalties (Kuhnert \& Lewis, 1987). Therefore, we propose:

Proposition 1. Individualizing delegation is positively related to the development of a dependent follower.

\subsubsection{Development through feedback}

Given that our main focus is ego development, we refer to feedback in the sense of providing information relevant to the limitations of a specific developmental stage of a person, rather than simply communicating how one is performing with respect to a chosen goal. More specifically, we are concerned with the use of dialectical types of feedback to facilitate developmental movement. There is ample evidence that suggest that different feedback methods such as devil's advocacy, dialectical inquiry, role plays, and expert opinion aid in reevaluation of assumptions, improvement in cognitive processes, better conceptualization of problems, and improvement in quality of decisions (e.g., Cosier, 1978; Nemeth, Connell, Rogers, \& Brown, 2001; Schweiger, Sandberg, \& Rechner, 1989; Schwenk, 1990). Because feedback does not involve sharing authority and power, it can be effectively used by both leaders and followers. In other words, in a leader-follower dyad, whoever is at a higher developmental order can use feedback to foster the development of the less advanced counterpart in the dyad. Independent and inter-independent leaders and followers may act very similarly to a coach when providing feedback to their dependent counterparts.

We mentioned above that the cognitive style of dependent individuals is marked by the use of stereotypes and the application of rules, norms, and procedures to solve problems, while their interpersonal style is marked by a deep concern for group cohesion, belonging, and avoidance of conflict. In contrast, independent individuals put logic ahead of norms and try to maximize the effectiveness of a given system, when solving problems. Independent individuals understand that conflict may uncover ways to improve system effectiveness, rather than just create tension. We define individualizing feedback as a dialectical form of feedback, provided by an independent or an inter-independent individual that criticizes norms, rules and procedures on the basis of their efficiency and effectiveness, and exposes the value of conflict. When following rules or norms leads to less than optimal outcomes, individualizing feedback provided to dependent-order individuals is likely to be disequilibrating because it would challenge their complete reliance on rules and norms.

Consider the account of the African-American manager presented earlier. His interpersonal style was marked by a strong norm to preserve his cultural identity, to the extent that he felt obligated to distance himself from his peers at work. However, counseling and feedback from his superiors led him to observe that other African-American executives had high-quality relationships with their white colleagues, and yet preserved their identity. This discourse provided evidence that questioned his concern for social acceptance and weakened his judgment regarding racial relations. This experience forced him to re-evaluate his decision regarding peer relations in terms of consequences and not in terms of conformity to social norms. Through this guidance 
and experience, he admitted that having collegial relationships with white colleagues was efficient for the organization and for his professional growth, and did not harm his personal identity.

Individualizing feedback involves direct communication between leaders and followers and is interpersonal in nature, by definition. Moreover, individualizing feedback challenges one's core assumptions and beliefs and therefore should elicit various emotional responses. In particular, if feedback is perceived as ego-threatening by the less advanced counterpart in a leaderfollower dyad, it may elicit negative emotions such as interpersonal tension, irritation, anger, and resentment (Baron, 1990; Stucke \& Sporer, 2002). In a similar manner, positive reception of feedback generates positive affect, feelings of confidence, and sense of deeper friendship and trust between source and recipient of feedback (London, 1995). Individualizing feedback is also personally salient, as it may influence a person's self-esteem and self-efficacy (London, 1995). In sum, we have argued that individualizing feedback can foster developmental movement because it is disequilibrating, emotionally engaging, interpersonal in nature and personally salient to the individual that receives it. Hence, we propose:

Proposition 2a. Individualizing feedback from an independent or an inter-independent follower is positively related to the development of a dependent leader.

Proposition $\mathbf{2 b}$. Individualizing feedback from an independent or an inter-independent leader is positively related to the development of a dependent follower.

\subsection{Challenging independent individuals}

\subsubsection{Development through participation}

Development from the independent to the inter-independent order is complex and rare. Past research has shown that most adults are either at a dependent order or are in a transition to an independent order, with very few (5\% to $8 \%$ ) ever reaching the interindependent order (Cook-Greuter, 2004; Laske, 2000; Torbert, 1994). However, given a suitable holding environment the movement to a higher order is possible and has been demonstrated in the past (Manners et al., 2004; White, 1985). Participation is an important developmental mechanism which can facilitate development to inter-independent order. Participation, or participative decision making, has been generally defined as a joint decision-making between a leader and a follower (Leana, 1987). Unlike delegation, which emphasized individual cognitive growth and autonomy, participation is rooted in philosophy that focuses on power equalization in social interactions occurring in the work place (Leana, 1987). We argue that a participative decision-making approach can be used in a fashion that creates disequilibrium for the cognitive and interpersonal styles of independent individuals.

To foster development, participation mechanisms should raise awareness, in the independent follower, that many problems can be viewed from multiple perspectives, that there can be several equally effective ways to solve a problem, and that the effectiveness of a system depends not only on the interaction between its parts, but also on the interaction of the system itself with other systems. Bartunek et al. (1983) describe this developmental process as gaining the ability to differentiate (i.e., perceive several dimensions in a given situation) and integrate (i.e., develop complex connections among the differentiated perspectives). Torbert, and Associates (2004) refer to this developmental movement as a shift from a systemic to an inter-systemic thinking.

We define integrative participation as the participation, under the guidance of an inter-independent leader, in decisions that are complex, ill-defined in terms of goals, and that involve multiple stakeholders with different points of view. Examples of integrative participation that requires inter-systemic thinking include strategy formulation, the design of organization-wide systems and processes, organizational change, and decision making in a multi-cultural environment (Bartunek et al., 1983; Drath, 2001; Torbert, 1994). For example, consider a case where a follower is given the opportunity to participate in the revision of the performance evaluation system of an organization. In this inter-systemic situation, the follower has a task of proposing a complex system that has organization-wide implications, involves various stakeholders and perspectives (e.g., employees and supervisors belonging to different departments each with its own job demands, issues, needs, and perspectives), and has multiple dimensions (e.g., different administrative and developmental implications, and various economic, relational, and psychological consequences of proposed performance evaluation system). In sum, this example describes a complex situation which would challenge a follower's current sense-making system and to provide an opportunity for developmental movement to occur.

We argue that integrative participation is disequilibrating for an independent follower's cognitive and interpersonal styles in several ways. First, the presence of multiple stakeholders creates a greater awareness for logics that may be different from one's own. At the independent order, individuals' cognitive style is governed by a self-crafted logic that is not brought into question. In the example mentioned above, a follower who is revising a performance management system may perceive the presence of multiple competing logics that defines an effective performance management system. Some stakeholders might view performance evaluation as a key developmental tool, some might perceive it as a bureaucratic nuisance, and yet many more might deem it as a political gimmick. The variety in stakeholders' perspectives and logic enables independent followers to question their beliefs in a "correct" logic.

Second, the lack of authority to impose a decision encourages the follower to propose solutions that respond to a variety of concerns. This is likely to be disequilibrating to their cognitive style because of the tendency of independent individuals to convince others to adopt their own interpretations (Fisher \& Torbert, 1991). In particular, independent individuals value others' opinions mostly as a way of better promoting their own goals and interpretations to others, which translates in an increased flexibility about the means to achieve their goals and, at the same time, an increased rigidity toward redefining goals, changing perspectives, and creating a shared vision. Integrative participation, on the other hand, requires being more flexible about both means and goals. 
Third, participation in decisions of inter-systemic nature may provide the independent followers the opportunity to observe the weakness of their current interpersonal style. According to Loevinger and Blasi (1976, p. 21), individuals at this stage act as their "brother's keeper." They feel responsible for other to the point of overstepping their autonomy in order to prevent them from making mistakes. Conflict is seen as potentially beneficial, but only if it results in clarification and better solutions (McCauley et al., 2006).The developmental movement to the inter-independent order requires adopting an interpersonal orientation that promotes respect for autonomy, tolerates differences in opinion, and accepts conflict as an inevitable source of transformation. For instance, in the above-mentioned example, the complexity of the situation would require interacting with diverse stakeholders over whom one lacks authority (e.g., senior management and managers working in other departments). In this case, learning to tolerate differences in opinions would be essential to proposing a solution that meets the needs of various stakeholders. An independent follower's participation in a complex problem provides an inter-independent leader the opportunity to guide the follower in learning how to collaborate with others in a tolerant manner.

Thus, integrative participation is disequilibrating to an independent follower's cognitive and interpersonal styles. Moreover, in inter-systemic assignments the complexity and difficulty associated with ill-defined goals are likely to make such assignments particularly salient. Similarly, the participation of multiple stakeholders with different points of view would possibly result in conflict, thus making the experience interpersonally and emotionally challenging. In sum, we have argued that integrative participation can foster developmental movement as it is disequilibrating, emotionally challenging, interpersonal in nature and salient to the individual that receives it. Thus, we propose:

Proposition 3. Integrative participation is positively associated with the development of independent followers.

\subsubsection{Development through feedback}

We have argued above that by exposing diversity of valid perspectives in complex situations and by emphasizing respect for autonomy, one may create disequilibrium in an independent-order person's cognitive and interpersonal styles. This disequilibrium can also be created through feedback from an inter-independent individual. For example, an inter-independent follower may help an independent leader understand people from different cultures by advocating the validity of culturally different perspectives. According to Bartunek et al. (1983), interacting with various stakeholders, empathizing with their concerns, and tolerating differences help manager better differentiate among, and integrate different perspectives. We define integrative feedback as feedback that centers on both recognizing the value of different perspectives and on offering ideas on how to integrate different perspectives into a broader perspective. To better illustrate the concept of integrative feedback, it is helpful to consider the following example.

A few years ago, while working for a company that was planning to implement a new ERP (i.e., enterprise resource planning) software, one of us witnessed a noteworthy instance of how inter-systemic problems may affect development movement. The head of the IT department was very enthusiastic about the ERP software, as he was convinced that the proposed solution would greatly improve efficiencies across the organization. To his surprise, the Head of the Finance department did not want to use the finance module offered with this software. The Finance department had been making significant investments in developing and implementing a customized finance and accounting software for the two preceding years. The employees in the Finance department had become familiar with the customized software and were reluctant to change to new software. The financial module, however, was a core module in the proposed ERP, without which the entire package was not expected to perform well. The IT director insisted that it was in the interest of the company to implement the full ERP solution and scrap the old finance and accounting software. The Finance director argued that doing so would be a waste of resources, and demanded that the ERP developer customize their software to work with the already existing finance software.

A follower in the IT department played a critical role in resolving this issue. The follower had considerable experience in managing and implementing IT solutions. He understood the complexity of the problem and encouraged the IT director to find a collaborative solution. The follower influenced the IT director to appreciate how the proposed IT solution impacts other systems (e.g., operations of Finance department) and processes in the organization (e.g., demotivation of employees in the Finance department who were involved in developing and implementing the customized solution currently in use). The emphasis on systems interactions enabled the IT director to revise his plan and collaborate to explore a more acceptable solution. The IT director worked with the Finance department to find out that with only minor modifications to the proposed ERP interface, the transition to the new ERP model would be much smoother. In essence, the follower's ability to argue how various business systems interact together and how each party had valid concerns exposed the two directors to the limitations of their cognitive and interpersonal styles.

Thus, we argue that integrative feedback is disequilibrating to an independent person's cognitive and interpersonal styles. As integrative feedback involves direct communication between leaders and followers thus, it is interpersonal in nature. Moreover, feedback challenges one's core assumptions and beliefs and therefore should elicit various emotional responses. Integrative feedback is also personally salient, as it may impact a person's self-esteem and self-efficacy (London, 1995). In sum, we have argued that integrative feedback can foster developmental movement as it is disequilibrating, emotionally engaging, interpersonal and personally salient to the individual that receives it. Thus, we propose:

Proposition 4a. Integrative feedback from an inter-independent follower is positively related to the development of an independent leader.

Proposition 4b. Integrative feedback from an inter-independent leader is positively related to the development of an independent follower. 


\section{LMX and the holding environment}

In order for development to occur, an environment that is conducive to development needs to be both created and nurtured. Kegan and Lahey (2001) argue that such a "holding environment" would both support and challenge the current meaning-making system of an individual. We focus, in this section, on the support function of the holding environment, which we suggest can be accurately represented, in the case of an agentic change, by the quality of relationship between leaders and followers. In trying to illustrate the concepts of support and challenge, Chaleff (2008) gave an account of a leader-follower dyad that suggests some of the problems that can occur when the two parties are at different developmental orders. In this account the leader had a tendency to micromanage, while the follower valued his autonomy. Yet, instead of challenging the leader and demanding more autonomy, the follower chose to provide increased support to the leader, until he developed a good relationship with her. Eventually the leader relaxed her management style, began to delegate and to empower her employees to a greater extent, and was better appreciated by all her subordinates.

Although Chaleff does not view the above-mentioned episode from a constructive-developmental point of view, the leader's tendency to micromanage and the follower's desire for autonomy suggest that the former was at the dependent order of development, while the latter was at the independent order of development. Because the leader could not be aware of the limitations of her current way of thinking, it would have been a mistake for the follower to demand a different style before a good relationship had been built. This story captures the importance of timeliness of challenges, but also the importance of relationship in determining that timeliness. Previous research has hinted toward the role of positive relationships in creating a good holding environment. For example Loevinger and Blasi (1976) suggested that good parents can be developmental pacers for their children via their intrinsic parental valuation that encourages children to take on challenges. These authors argue that the same phenomenon explains why individuals develop when good teachers and good therapists create environments of positive regard and mutual trust. We suggest here that the quality of a work relationship may play a very similar role in the ego development of individuals.

The quality of relationship between leaders and followers is often discussed in leadership theories. Leader-member exchange theory (LMX; e.g., Dansereau et al., 1973; Dansereau, Graen, \& Haga, 1975; Graen \& Cashman, 1975) stands out from most other leadership theories through its focus on the dyadic relationship between a leader and a follower (i.e., a member) (Gerstner \& Day, 1997). The theory suggests that the quality of relationship between the leader and the member will have consequences for individuals, groups, and the organization as a whole. LMX theories suggest that in a high LMX relationship both the leader and the follower provide more support to each other and their relationship is characterized by increased flexibility and trust (Ferris et al., 2009). For example, research has shown that followers in high LMX relationships are more likely to perform organizational citizenship behaviors, especially behaviors that target leaders (Ilies, Nahrgang, \& Morgeson, 2007). In return, leaders tend to offer more organizational resources and rewards to high LMX followers (Henderson, Wayne, Shore, Bommer, \& Tetrick, 2008). In terms of flexibility and trust, leaders may offer increased job latitude or delegation to high LMX followers (Bauer \& Green, 1996). Research has also shown that high LMX employees are more likely to respond positively to managerial influence tactics (Furst \& Cable, 2008), to seek negative feedback from their supervisors (Chen, Lam, \& Zhong, 2007), and to display sportsmanship at work (Henderson et al., 2008)-a particular type of organizational citizenship behavior (e.g. Organ, 1988) which has to do with tolerating temporary inconveniences or difficulties at work. This research suggests high LMX employees are more likely to respond positively to difficult challenges.

All in all, there is ample evidence in the LMX literature to suggest that a high LMX relationship meets the criteria of a supportive holding environment. Both leaders and followers in high LMX relationships are more likely to respond positively to their counterparts' actions that drive developmental movement. At the same time, developmental interventions (i.e., participation, delegation, and feedback) are likely to be more salient to both parties involved when there is a positive relationship between them. Thus, we propose:

Proposition 5. LMX will moderate the relationship between challenging actions by leaders and followers and the developmental movement of the counterpart, such that development will be more likely when LMX is high rather than when LMX is low.

\section{Directions for future research}

Ego development theories have had minimal influence upon the mainstream management and leadership literature (McCauley et al., 2006). This is unfortunate, as these theories have considerable potential in terms of creating a complex understanding of people and situations in managers-an ability which is likely to add significant value to organizations (Bartunek et al., 1983). In this paper, we utilized a constructive-developmental approach to suggest that leaders and followers can help each other develop a more complex understanding of organizational matters. For development to occur, a delicate balance of support and challenge needs to be attained. The challenge has the role of exposing the limitations of the thinking pattern operating at a certain stage. The support has the role of creating a safe holding environment in which the individual feels confident to take on the new challenge.

We have suggested that feedback, participation, and delegation, which are typical follower and leader interactions, can be tailored to the specific limitations of each developmental stage, such as to challenge the current framework of thinking and to foster development. For example, we suggested that development from the dependent to the independent order can be seen as a shift from a thinking framework governed by loyalty to individuals and groups, and by adherence to norms and rules, to an advanced thinking framework centered on efficiency and effectiveness. Similarly, development from the independent to the inter- 
independent order can be seen as a change from defining and promoting one's own perspectives and standards to understanding the value of different perspectives and integrating diverse viewpoints.

The testing of the propositions advanced in this paper would require a longitudinal design tailored to the specifics of each transition (i.e., from dependent to independent, or from independent to inter-independent). For example, we proposed that the transition from the dependent to the independent order can be fostered through delegation of assignments that create loyalty conflicts (i.e., individualizing delegation) and through providing critical feedback on rules and norms on the basis of efficiency and effectiveness (i.e., individualizing feedback). To test these propositions, a validated measure of ego development stage, such as the Washington University Sentence Completion Test (e.g., Loevinger \& Wessler, 1970), or the subject-object test (Lahey, Souvaine, Kegan, Goodman, \& Felix, 1988) administered at the beginning of a research study would capture the current frame of thinking of both leaders and followers involved in the study. At the same time a measure of the quality of leader-member relationship (LMX) could be administered to assess the degree of support that individuals in these relationships are likely to get. Measures of loyalty conflict and effectiveness based criticism of rules and norms can be administered at a later time to assess the developmental challenges that the leader-follower relationship raises. These constructs can be measured through self-response questionnaires. Examples of items could include questions that ask followers how often delegated assignments require them to perform boundary spanning roles. Similarly, both followers and leaders could be asked how often they criticize the use of rules or norms that result in suboptimal outcomes. The study should conclude with another administration of the ego development questionnaire. This second administration should allow sufficient time for development to occur.

To account for alternative explanations, such studies should control for general intelligence, gender, and age. Loevinger and Blasi (1976) have suggested that general intelligence may impact the maximum potential for development. A control for gender would help to account for the possibility that delegation and feedback, as developmental mechanisms, may work differently for men and women. Many studies have suggested that there is a correlation between developmental order and age (Manners \& Durkin, 2001). In terms of personality, Loveniger views ego as a master trait which encompasses personality (Loevinger \& Blasi, 1976), and there is little evidence that suggests that personality traits are related to developmental order. For example, Strang and Kuhnert (2009) found no relation between Big five personality constructs and a leader's developmental order. Similarly, McCrae and Costa's (1980) study found that traits of neuroticism and extraversion were unrelated to developmental order. However, this study showed that openness to experience correlated positively with developmental order. Therefore, studies must control for openness to experience.

There are several avenues of research that the propositions advanced in this paper suggest. We have argued that leaderfollower dyads, where one individual is more developmentally advanced, can foster the development of the other individual. However, in a real setting any leader might have several followers at different stages of development, which may play different roles in the leader's development. Similarly, followers' development may also be influenced by peers at different levels of development. In essence, individuals will be exposed to a network of relationship, not just dyadic relationships, which may have a more complex impact on the development of individuals. McCauley et al. (2006) talked about the existence of "social systems that produce leadership" (p. 650). It is possible that there are also social systems that foster or hinder development. For example, is development more likely in a social system where most individuals are more advanced than the focal individual, or would this type of environment provide too much challenge and not enough support? Also, what will be the relative influence of peers as compared to leaders, over the development of a follower?

Related to the idea of a social system, McCauley and colleagues reported evidence of leadership cultures that can be described by different developmental stages (McCauley et al., 2008). Our propositions suggest that leaders and followers may have a direct role in building more developmentally advanced leadership cultures, by fostering the development of others through delegation and feedback. The extent to which this may happen is a matter for empirical studies to clarify. For example, can a few dyadic relationships that have a developmental component actually result in organization wide leadership culture change?

Another interesting area to explore would be the impact that developmental stages may have on the quality of relationship that develops between a leader and a follower. In this paper we have suggested that the already established and relatively stable LMX level will influence the developmental impact of leader and follower interventions (i.e., delegation, participation, and feedback). However, developmental orders may also play a role in how the relationship develops in the first place. Past research has suggested various factors that influence the development of LMX in new relationships. For example, Maslyn and Uhl-Bien (2001) showed that the effort expended toward the development of LMX relationships influences the quality of these relationships. Moreover, Engle and Lord (1997) found that better LMX relationship formed when the leader and the follower shared the same implicit performance theory (ideas about what constitutes competent performance). Developmental levels have been shown to influence what individuals expect in terms of performance and behaviors from their leaders and from their followers (McCauley et al., 2006). Thus, it is possible that developmental stages may also influence what kind of LMX relationships develop among individuals. For example, dependent followers might expect clear guidance and direction from leaders and, may be more likely to develop high LMX relationships with dependent leaders, who are more likely to use regulations, rules and authority in decision making.

The question of how developmental orders may influence the formation of high exchange relationship between a leader and a follower becomes even more important in today's diverse work environment. Past research has shown that perceived similarity is a strong correlate of LMX (Bauer \& Green, 1996; Liden, Wayne, \& Stilwell, 1993). However, the constructive developmental literature suggests that individuals at the highest stages of development (i.e., inter-independent) tolerate and appreciate diversity. It is possible that individuals with advanced ego levels may more easily develop high LMX relationships, in spite of their demographic or cultural differences. It is also evident from decades of workplace diversity research that perceptions of similarity 
on attributes ranging from demographic attributes to attitudes and values increase interpersonal attraction and liking (Williams \& O'Reilly, 1998). The ego is a broad dimension of individual differences found in any age cohort (Loevinger \& Blasi, 1976). Moreover, the meaning-making principles employed at each developmental stage are similar in all individuals at that stage and, thus, may represent a source of perceived similarity for otherwise diverse individuals. It would be fruitful to explore how understanding each others' developmental orders would enable leaders and followers to create high-exchange relationships despite having surfacelevel demographic differences. This avenue of research would also answer the call of diversity researchers who challenge the practice of focusing on the superficial diversity attributes (e.g., Hamdani \& Buckley, 2011; Van de Ven, Rogers, Bechara, \& Kangyong, 2008) and urge researchers to focus on deep-level differences and similarities among individuals.

Following a constructive-developmental approach, we have suggested that developmental interventions of both leaders and followers need to be tailored to the specific needs that an individual has at his/her respective developmental stage. This principle may have fruitful applications to other theories concerned with the development of individuals. For example, it is possible that mentoring relationships may be more successful and more satisfying to both the mentor and the protégé when the mentor takes into account the limitations of the developmental stage of the protégé. It is also possible that the developmental stage of the mentor and protégé will influence how the relationship plays out in the separation phase, and may explain why some protégés separate harmoniously or destructively. For example, when both mentor and protégé are at the independent stage in the separation phase, there may be more conflict of ideas and work styles, as each individual will try to convince the other of the superiority of their perspective. In contrast, an inter-independent mentor is likely to be more tolerant and open to different perspectives, thus allowing for less mentor-protégé separation conflict.

\section{Conclusion}

In this paper, we have proposed an extension to the theory explaining the process of constructive co-development of leaders and followers. In our proposed extension, we argue that this process entails the on-going and reciprocal development of both leaders' and followers' meaning-making models. Specifically, we claim that their meaning-making models are likely to progress when the nature of interactions, over time, between leaders and followers involves higher levels of cognitive and interpersonal complexity. The most desired outcome of this process is the emergence of a learning organization with the developmental practices of delegation, participation and feedback-giving and a collective capacity to produce direction, alignment and commitment (Drath et al., 2008).

For the co-development of leaders and followers to engender organizational learning, it is most critical to enact the right context, as contextual factors are likely to signal potential moderators or boundary conditions for our proposed theoretical extension. Most likely candidate factors are the absorptive capacity of the organization and its members to develop and learn under the condition of increasing environmental complexity and interpersonal trust. This is crucial for openness to change to be exhibited by both leaders and followers. If these factors are not present in the organization, the process of co-development of leaders and followers will be stalled, as mutual inquiry and learning will be stunted. Therefore, it might be that this process of codevelopment will be sustainable only in cases when a commensurate accountability system is designed and implemented. This means that the development of a multi-level model will be the next theoretical step in developing our proposed extension.

In summary, we argue that the recognition of the agentic role of followers in the process of leadership development is critical for us to effectively move forward leadership inquiry toward a collective paradigm. In this direction, we have discussed only one of the myriad possible ways in which this might happen. Our hope is that our proposed extension will facilitate a movement away from the stunting notion that leadership is concentrated in the "sparkling whitecaps we know as leaders." This broadening conceptualization of leadership development as co-development will help us more fully understand how leaders and followers have a reciprocal influence upon each other. In effect, this will truly be a situation in which life imitates art.

\section{References}

Avolio, B. J., Bass, B. M., \& Jung, D. I. (1999). Re-examining the components of transformational and transactional leadership using the multifactor leadership. Journal of Occupational and Organizational Psychology, 72(4), 441-462.

Baldwin, T. T., \& Magjuka, R. J. (1997). Training as an organizational episode: Pretraining influences on trainee motivation. In J. K. Ford, S. W. J. Kozlowski, K. Kraiger, E. Salas, \& M. S. Teachout (Eds.), Improving training effectiveness in work organizations (pp. 99-127). Mahwah, NJ: Erlbaum.

Baron, R. A. (1990). Countering the effects of destructive criticism: The relative efficacy of four interventions. Journal of Applied Psychology, 75(3), 235-245.

Bartunek, J. M., Gordon, J. R., \& Weathersby, R. P. (1983). Developing a 'complicated' understanding of administrators. Academy of Management Review, 8(2), 273-284.

Bass, B. (1985). Leadership and performance beyond expectations. New York: Free Press.

Bauer, T. N., \& Green, S. G. (1996). Development of leader-member exchange: A longitudinal test. Academy of Management Journal, 39(6), 1538-1567.

Block, J. (1995). Assimilation, accommodation, and the dynamics of personality development. Child Development(2), 281-295.

Cascio, W. F. (1982). Whither industrial and organizational-psychology in a changing world of work. American Psychologist, 50(11), 928-939.

Chaleff, I. (2008). Creating new ways of following. In R. E. Riggio, I. Chaleff, \& J. Lipman-Blumen (Eds.), The art of followership: How great followers create great leaders and organizations (pp. 67-87). San Francisco, CA: Jossey-Bass.

Chen, Z., Lam, W., \& Zhong, J. A. (2007). Leader-member exchange and member performance: A new look at individual-level negative feedback-seeking behavior and team-level empowerment climate. Journal of Applied Psychology, 92(1), 202-212.

Cook-Greuter, S. R. (2004). Making the case for a developmental perspective. Industrial E' Commercial Training, 36(6/7), 275-281.

Cosier, R. A. (1978). The effects of three potential aids for making strategic decisions on prediction accuracy. Organizational Behavior E Human Performance, 22(2), 295-306.

Dansereau, F., Cashman, J., \& Graen, G. (1973). Instrumentality theory and equity theory as complementary approaches in predicting the relationship of leadership and turnover among managers. Organizational Behavior \& Human Performance, 10(2), 184-200. 
Dansereau, F., Graen, G., \& Haga, W. J. (1975). A vertical dyad linkage approach to leadership within formal organizations: A longitudinal investigation of the role making process. Organizational Behavior E Human Performance, 13(1), 46-78.

DeRue, D. S., \& Wellman, N. (2009). Developing leaders via experience: The role of developmental challenge, learning orientation, and feedback availability. Journal of Applied Psychology, 94(4), 859-875.

Drath, W. (2001). The deep blue sea: Rethinking the source of leadership. San Francisco: Jossey-Bass.

Drath, W. H., McCauley, C. D., Palus, C. J., Van Velsor, E., O'Connor, P. M. G., \& McGuire, J. B. (2008). Direction, alignment, commitment: Toward a more integrative ontology of leadership. Leadership Quarterly, 19(6), 635-653.

Dvir, T., \& Shamir, B. (2003). Follower developmental characteristics as predicting transformational leadership: A longitudinal field study. Leadership Quarterly, 14(3), 327-344.

Engle, E. M., \& Lord, R. G. (1997). Implicit theories, self-schemas, and leader-member exchange. Academy of Management Journal, 40(4), 988-1010.

Feldman, D. C. (1988). Managing careers in organizations. Glenview, IL: Scott Foresman \& Co.

Ferris, G. R., Liden, R. C., Munyon, T. P., Summers, J. K., Basik, K. J., \& Buckley, M. R. (2009). Relationships at work: Toward a multidimensional conceptualization of dyadic work relationships. Journal of Management, 35(6), 1379-1403.

Fisher, D., \& Torbert, W. R. (1991). Transforming managerial practice: Beyond the achiever stage. Research in Organizational Change and Development, 5, 143-173.

Furst, S. A., \& Cable, D. M. (2008). Employee resistance to organizational change: Managerial influence tactics and leader-member exchange. Journal of Applied Psychology, 93(2), 453-462.

Gerstner, C. R., \& Day, D. V. (1997). Meta-analytic review of leader-member exchange theory: Correlates and construct issues. Journal of Applied Psychology, 82(6), $827-844$

Graen, G., \& Cashman, J. (1975). A role-making model of leadership in formal organizations: A developmental approach. Leadership frontiers, $143,165$.

Hamdani, M. R., \& Buckley, M. R. (2011). Diversity goals: Reframing the debate and enabling a fair evaluation. Business Horizons, 54, 33-40.

Helsing, D., Drago-Severson, E., \& Kegan, R. (2004). Applying constructive-developmental theories of adult development to ABE and ESOL practices. In J. Comings, B. Garner, \& C. Smith (Eds.), Review of adult learning and literacy, 4. (pp. 157-197): Lawrence Erlbaum.

Henderson, D. J., Liden, R. C., Glibkowski, B. C., \& Chaudhry, A. (2009). LMX differentiation: A multilevel review and examination of its antecedents and outcomes. Leadership Quarterly, 20, 517-534.

Henderson, D. J., Wayne, S. J., Shore, L. M., Bommer, W. H., \& Tetrick, L. E. (2008). Leader-member exchange, differentiation, and psychological contract fulfillment: A multilevel examination. Journal of Applied Psychology, 93(6), 1208-1219.

Hirsch, J. A. (1988). Toward a cognitive-developmental theory of strategy formulation among practicing physicians. Boston, Massachusetts: Boston University.

Horgan, D. D., \& Simeon, R. J. (1990). Mentoring and participation: An application of the Vroom-Yetton model. Journal of Business and Psychology, 5(1), 63-84.

Hyde, C. R. (2000). Pay it forward: Simon and Schuster.

Ilies, R., Nahrgang, J. D., \& Morgeson, F. P. (2007). Leader-member exchange and citizenship behaviors: A meta-analysis. Journal of Applied Psychology, 92(1), $269-277$.

Kegan, R. (1980). Making meaning: The constructive-developmental approach to persons and practice. The Personnel and Guidance Journal, 58(5), 373-380.

Kegan, R. (1982). The evolving self: Problem and process in human development. Cambridge, MA: Harvard University Press.

Kegan, R., \& Lahey, L. L. (2001). How the way we talk can change the way we work: Seven languages for transformation.

Klein, K. J., Ziegert, J. C., Knight, A. P., \& Yan, X. (2006). Dynamic delegation: Shared, hierarchical, and deindividualized leadership in extreme action teams. Administrative Science Quarterly, 51(4), 590-621.

Kohlberg, L. (1969). Stage and sequence: The cognitive developmental approach to socialization. In D. Goslin (Ed.), Handbook of socialization: Theory and research. New York: Rand McNally.

Kohlberg, L. (1987). The psychology of moral development. San Francisco: Harper \& Row.

Kram, K. E. (1983). Phases of the mentor relationship. Academy of Management Journal, 26(4), 608-625.

Kuhnert, K. W. (1994). Transforming leadership: Developing people through delegation. In B. M. Bass, \& B. J. Avolio (Eds.), Improving organizational effectiveness through transformational leadership (pp. 10-25). Thousand Oaks, CA: Sage Publications Inc.

Kuhnert, K. W., \& Lewis, P. (1987). Transactional and transformational leadership: A constructive/developmental analysis. Academy of Management Review, 12(4), 648-657.

Lahey, L., Souvaine, E., Kegan, R., Goodman, R., \& Felix, S. (1988). A guide to the subject-object interview: Its administration and interpretation. Cambridge, MA: Harvard University Graduate School of Education Subject-Object Research Group.

Laske, O. E. (1999). An integrated model of developmental coaching. Consulting Psychology Journal: Practice and Research, 51(3), $139-159$.

Laske, O. E. (2000). Foundations of scholarly consulting: The developmental structure/process tool (dspt). Consulting Psychology Journal: Practice and Research, 52(3), $178-200$.

Leana, C. R. (1987). Power relinquishment versus power sharing: Theoretical clarification and empirical comparison of delegation and participation. Journal of Applied Psychology, 72(2), 228-233.

Liden, R. C., Wayne, S. J., \& Stilwell, D. (1993). A longitudinal study on the early development of leader-member exchanges. Journal of Applied Psychology, 78(4), $662-674$.

Loevinger, J., \& Blasi, A. (1976). Ego development: Conceptions and theories. San Francisco: Jossey-Bass.

Loevinger, J., \& Wessler, R. (1970). Measuring ego development. Construction of a sentence completion test, 1, San-Francisco: Jossey-Bass.

London, M. (1995). Giving feedback: Source-centered antecedents and consequences of constructive and destructive feedback. Human Resource Management Review, 5(3), 159-188.

Manners, J., \& Durkin, K. (2000). Processes involved in adult ego development: A conceptual framework. Developmental Review, 20 (4), 475-513.

Manners, J., \& Durkin, K. (2001). A critical review of the validity of ego development theory and its measurement. Journal of Personality Assessment, 77(3), 541-567.

Manners, J., Durkin, K., \& Nesdale, A. (2004). Promoting advanced ego development among adults. Journal of Adult Development, 11 (1), $19-27$.

Maslyn, J., \& Uhl-Bien, M. (2001). Leader-member exchange and its dimensions: Effects of self-effort and other's effort on relationship quality. Journal of Applied Psychology, 86(4), 697-708.

Mayo, A. (2000). The role of employee development in the growth of intellectual capital. Personnel Review, 29(4), 521-533.

McCall, M. W., Lombardo, M. M., \& Morrison, A. M. (1988). The lessons of experience: How successful executives develop on the job. Lexington, MA: Free Press.

McCauley, C. D. (1986). Developmental experiences in managerial work: A literature review. Greensboro, NC: Center for Creative Leadership.

McCauley, C. D., Drath, W. H., Palus, C. J., O'Connor, P. M. G., \& Baker, B. A. (2006). The use of constructive-developmental theory to advance the understanding of leadership. Leadership Quarterly, 17(6), 634-653.

McCauley, C., Palus, C., Drath, W., Hughes, R., McGuire, J., O'Connor, P., et al. (2008). Interdependent leadership in organizations: Evidence from six case studies. Greensboro, NC: Center for Creative Leadership.

McCauley, C. D., Ruderman, M. N., Ohlott, P. J., \& Morrow, J. E. (1994). Assessing the developmental components of managerial jobs. Journal of Applied Psychology, 79(4), 544-560.

McCrae, R. R., \& Costa, P. T. (1980). Openness to experience and ego level in Loevinger's sentence completion test: Dispositional contributions to developmental models of personality. Journal of Personality and Social Psychology, 39(6), 1179-1190.

Merron, K., Fisher, D., \& Torbert, W. R. (1987). Meaning making and management action. Group E Organization Studies, $12(3), 274-286$.

Nemeth, C. J., Connell, J. B., Rogers, J. D., \& Brown, K. S. (2001). Improving decision making by means of dissent. Journal of Applied Social Psychology, 31(1), 48-58. Nicholson, N. (1984). A theory of work role transitions. Administrative Science Quarterly, 29(2), 172-191.

Nicholson, N., \& West, M. A. (1988). Managerial job change: Men and women in transition. Cambridge, England: Cambridge University Press.

Organ, D. W. (1988). Organizational citizenship behavior: The good soldier syndrome. Lexington, MA: Lexington Books.

Palus, C. J., \& Drath, W. H. (1995). Evolving leaders: A model for promoting leadership development in programs. Greensboro, NC: Center for Creative Leadership.

Pfaffenberger, A. (2005). Optimal adult development: An inquiry into the dynamics of growth. Journal of Humanistic Psychology, 45(3), $279-301$.

Rooke, D., \& Torbert, W. R. (2005). Seven transformations of leadership. Harvard Business Review, 83(4), 66-76. 
Schweiger, D. M., Sandberg, W. R., \& Rechner, P. L. (1989). Experiential effects of dialectical inquiry, devil's advocacy, and consensus approaches to strategic decision making. Academy of Management Journal, 32(4), 745-772.

Schwenk, C. R. (1990). Effects of devil's advocacy and dialectical inquiry on decision making: A meta-analysis. Organizational Behavior E Human Decision Processes, 47(1), 161-176.

Smith, S. E. (1980). Ego development and the problems of power and agreement in organizations. Washington, DC: George Washington University.

Strang, S. E., \& Kuhnert, K. W. (2009). Personality and leadership developmental levels as predictors of leader performance. Leadership Quarterly, 20(3), 421-433.

Stucke, T. S., \& Sporer, S. L. (2002). When a grandiose self-image is threatened: Narcissism and self-concept clarity as predictors of negative emotions and aggression following ego-threat. Journal of Personality, 70(4), 509-532.

Torbert, W. R. (1987a). Education for organizational and community self-management. In S. B. J. Meehan (Ed.), Beyond the market and the state (pp. 171-184). Philadelphia: Temple University Press.

Torbert, W. R. (1987b). Managing the corporate dream: Restructuring for long-term success. Homewood, IL: Dow Jones-Irwin.

Torbert, W. R. (1991). The power of balance: Transforming self, society, and scientific inquiry. Newbury Park, CA: Sage Publications, Inc.

Torbert, W. R. (1994). Cultivating postformal adult development: Higher stages and contrasting interventions. In M. E. Miller \& S.R. Cook-Greuter (Eds.), Transcendence and mature thought in adulthood: The further reaches of adult development (pp. 181-203). : Rowman \& Littlefield Publishers, Inc.

Torbert, \& Associates (2004). Action inquiry: The secret of timely and transforming leadership. San Francisco, CA: Berrett-Koehler.

Van de Ven, A. H., Rogers, R. W., Bechara, J. P., \& Kangyong, S. (2008). Organizational diversity, integration and performance. Journal of Organizational Behavior, 29(3), 335-354.

Weick, K. E. (1979). The social psychology of organizing (2nd ed.). Reading, MA: Addison-Wesley.

Wenger, E., \& Snyder, W. M. (2000). Communities of practice: The organizational frontier. Harvard Business Review, 78(1), $139-145$.

White, M. S. (1985). Ego development in adult women. Journal of Personality, 53(4), 561-574.

Williams, K. Y., \& O'Reilly, C. A. (1998). Demography and diversity in organizations: A review of 40 years of research. In B. Staw \& R. Sutton (Eds.), Research in Organizational Behavior, 20. (pp. 77-140)Greenwich, CT: JAI Press.

Yukl, G., \& Fu, P. P. (1999). Determinants of delegation and consultation by managers. Journal of Organizational Behavior, 20(2), $219-232$. 